УДК 636.01

\title{
К ВОПРОСУ О СТАНОВЛЕНИИ ЩЕНКОВ CANIS FAMILIARIS (L.) (ENGLISH COKER SPANIEL) B PAHHEM ПОСТНАТАЛЬНОМ ОНТОГЕНЕЗЕ
}

\author{
Дыбан П.А. \\ ФГБНУ«Институт экспериментальной медициньл», Санкт-Петербург, e-mail: pavandy@mail.ru
}

\begin{abstract}
Был проведен морфофункциональный анализ развития 572 щенков (110 пометов) английского кокер спаниеля на протяжении 30-40 суток после рождения. На ранних этапах постнатального онтогенеза были изучены: количество щенков в помете, летальность в первые дни после рождения, динамика массы тела, формирование локомоторных и голосовых реакцмй. зрение, слух, зубная формула. Полученные данные о морфофункциональном развитии щенков могут иметь практическое значение с точки зрения объективного контроля не только за развитием щенков и возможной коррекции в схеме их питания, но и одного из критериев в дальнейшем выборе питомца, чьи данные как соответствуют нормальному развитию, так и опережают средние показатели. Сравнительный анализ полученных нами данных с литературными показал, что морфофункциональное развитие щенков различных пород происходит стереотипно.
\end{abstract}

Ключевые слова: щенки английского кокер-спаниеля, количество щенков в помете, летальность, динамика массы тела, локомоторные и голосовые реакции,зубная формула, зрение, слух

\section{TO THE QUESTION ABOUT THE DEVELOPMENT OF THE PUPPIES CANIS FAMILIARIS (L.) (ENGLISH COKER SPANIEL) IN EARLY POSTNATAL ONTOGENEZIS}

\section{Dyban P.A.}

Institute of Experimental Medicine, St-Petersburg, e-mail: pavandy@mail.ru

\begin{abstract}
It was conducted a morphological analysis of the development 572 puppies (110 litters) English Cocker Spaniel for 30-40 days after birth. In the early stages of postnatal ontogenesis was studied: the number of puppies in the litter, mortality in the first days after birth, the dynamics of body weight, the formation of locomotor and voice reaktsii. vision, hearing, dentition. The obtained data on the morphofunctional development of puppies can have practical importance from the point of view of objective control not only of puppies and a possible correction in the scheme of their power, but one of the criteria in the further selection of a pet whose data as correspond to normal development, and ahead of the average. A comparative analysis of the obtained data with the literature showed that the morphological and functional development of thepuppies happens stereotypical.
\end{abstract}

Keywords: puppies, English Cocker Spaniel, number of pups in a litter, mortality, the dynamics of body weight, dentition, vision, locomotor and voice response

Ранние этапы постнатального онтогенеза играют значительную роль в формировании и дальнейшем нормальном функционировании индивидуума. В это время происходит определенное становление различных систем, обусловленных, в частности, степенью цитодифференцировки клеток и постнатальным гистогенезом. Знание же временных параметров различных морфофункциональных данных в те или иные сроки раннего постнатального развития позволяет судить и о нормальном /аномальном развитии той или иной системы и организма в целом. В связи с этим, целью нашего исследования являлось изучение развития щенков английского кокер спаниеля с обращением особого внимания на имеющиеся литературные данные о становлении щенков других пород собак.

\section{Материалы и методы исследования}

В настоящей статье обобщены результаты наших 10-летних наблюдений за развитием 572 щенков (110 пометов) породы английский кокер-спаниель (часть популяции Санкт-Петербургского разведения). Были исследованы:

- количество щенков в помете, распределение по полу, масса их тела, смертность в первые дни после рождения;

- динамика прироста массы тела щенков в течение 30 суток после рождения;

- сроки: открытия глазной щели, реакции на звуки, прорезывания зубов, формирования локомоторных (поступательное движение) и голосовых реакций ( взлаивание, рычание и т.п.).

\section{Результаты исследования и их обсуждение}

1. Количество щуенков в помете, их вес, распределение по полу, смертность

Помет, в среднем, представлен 5-6 щенками $(5,2 \pm 1,7)$. Существующий разброс (от 1 до 9) в исследованных нами 110 выводках обусловлен разнообразными факторами, в том числе и генетическими, определяющими количество созревающих яйцеклеток, кроме того внутриутробной смертностью плодов, а также правильностью определения сроков проведения вязки и т.д. 
Соотношение родившихся кобелей и сук в исследованной нами популяции (более 560 щенков) составляет $1: 0,94$.

Не вдаваясь в расшифровку причин, вызывающих смертность щенков, наблюдавшуюся, как правило, в первые четверо суток после рождения, необходимо отметить, что летальность в исследованной нами популяции составила $4,4 \% \pm 1,2$.

Средний вес новорожденных щенков, по нашим данным, составляет 228 г \pm 35 и не зависит ни от очередности их рождения, ни от возраста родителей. Средний вес новорожденных кобелей на $15 \%$ больше среднего веса сук. Предельно максимальный вес новорожденных, по нашим данным, достигает 350 г и чаще всего наблюдается в пометах, представленных 1-2 щенками. Самый минимальный вес оказался равным 70 г и был обнаружен у суки, родившейся в помете из 8 щенков.

2. Динамика прироста массы тела щенков

На рисунке приведены обобщенные сведения о динамике массы тела щенков английского кокер спаниеля. Как было написано ранее, средний вес новорожденных оказался равным $228 \Gamma \pm 35$. ток после рождения, происходит вне зависимости от первоначального веса новорожденных и их пола. Такой ежедневный прирост выражен настолько четко, что можно практически без существенных погрешностей прогнозировать ожидаемый вес щенков в будущем. Несоответствие реальной массы по отношению к теоретическому приросту должно служить сигналом для принятия соответствующих мер к щенкам, запаздывающим в развитии (дополнительное индивидуальное кормление материнским молоком, подкладывание под лучший молочный сосок и т.д). Необходимо отметить, что на более поздних сроках развития щенков, питающихся не только материнским молоком, но и различными продуктами растительного и животного происхождения, описанная выше динамика прироста веса сохраняется, хотя возможны и различного рода флюктуации. Удвоение веса щенков происходит через 8 суток после рождения. Масса тела 14-,18-, 30- и 34-суточных щенков соответственно в 3-, 4-, 6,8-, и 8 раз больше, чем у новорожденных. Средняя масса тела 30 суточных щенков составляет 1550 г \pm 120.

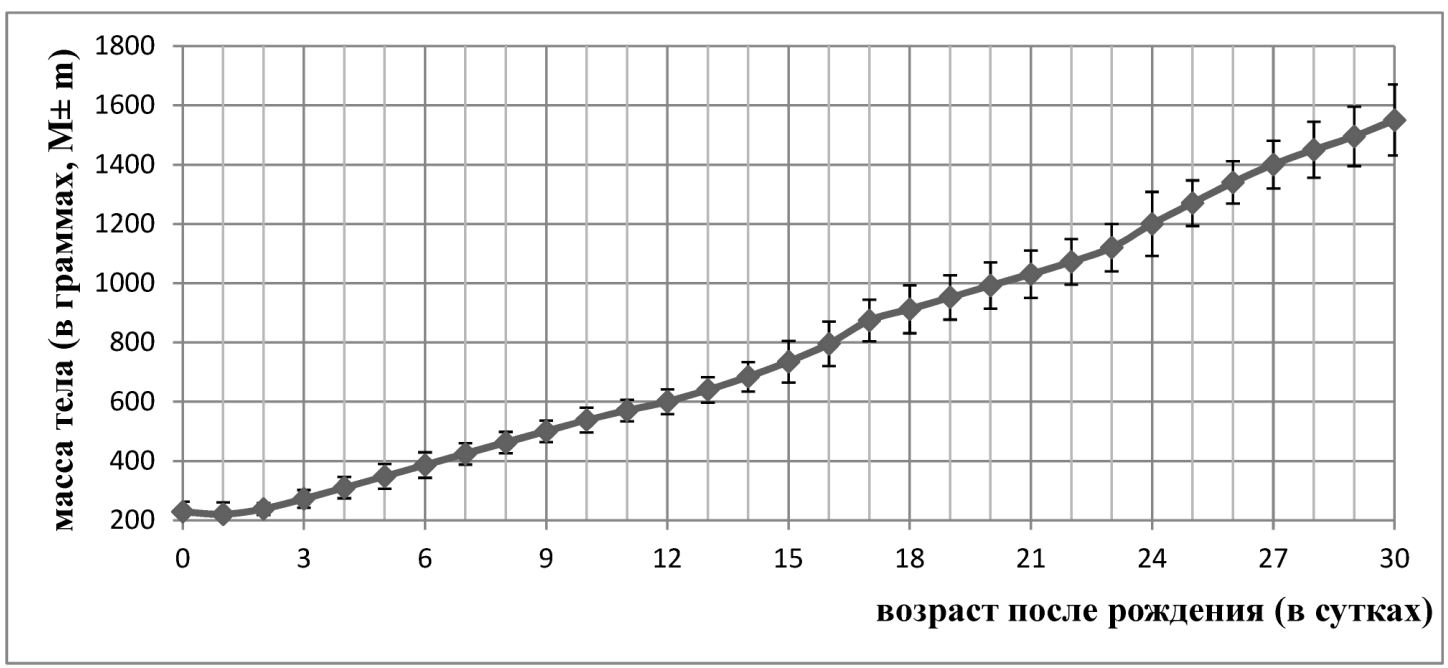

Динамика прироста массы тела щенков английского кокер спаниеля в разные сроки после рождения

Лишь через 2 суток после рождения щенки начинают прибавлять в весе (в \% от веса новорожденных): через 2 суток этот показатель составляет 5-8\% (до 18 г), через 3 суток $-15-20 \%$ ежедневно, т.е. примерно по 38 г. Необходимо отметить, что ежедневное увеличение массы тела щенков на $15-20 \%$ (в \% от веса новорожденных), начавшееся через 3 су-
3. Некоторые морфофункииональные показатели развития щенков английского кокер-спаниеля

В данном разделе работы приводятся, в основном, те показатели развития щенков английского кокер-спаниеля, которые достаточно подробно описаны для других пород охотничьих собак в известных руководствах по кинологии [1-9] (табл.). 
Известно, что щенки рождаются слепыми, вернее с плотно спаянными верхним и нижним веками.По нашим данным, глазная щель у щенков английского кокер-спаниеля открывается, как правило, через 10 - 11 суток после рождения. Самое раннее начало процесса открывания век было обнаружено у 7 суточного щенка.

Через 13-14 суток после рождения щенки начинают активно реагировать на посторонние звуки. Первые не очень уверенные попытки ходить обнаруживаются у 14-15 суточных щенков. Через 15-16 суток после рождения щенки начинают лаять.

Первые молочные зубы начинают прорезываться у 21-23 суточных щенков. В возрасте 30-35 суток щенки имеют полностью сформированные (вышедшие на всю длину) 16 зубов (резцы и клыки), а еще 6 только начинают выходить из - под десен (2 на верхней и 4 на нижней челюстях). В возрасте 36-40 суток у щенков полностью сфор- мировано 20 (реже 18) зубов и неполностью вышли из-под десен еще 4 (реже 6). Необходимо отметить, что у $36-40$ суточных щенков количество зубов вышедших на всю длину на нижней челюсти больше, чем на верхней.

Сопоставление полученных нами данных с литературными свидетельствует о том, что морфофункциональные показатели развития щенков английского кокерспаниеля, приведенные в этом разделе статьи, принципиально не отличаются от параметров развития собак других пород.

Необходимо подчеркнуть, что в ряде случаев производилось не только изучение параметров развития всех щенков отдельных пометов до 30-35 суток, но и прослеживалась их дальнейшая судьба. Наши наблюдения свидетельствуют о том, что очередность рождения щенка ни в коем случае не влияет ни на его динамику развития, ни на экстерьерные и рабочие качества взрослой собаки.

Некоторые морфофункциональные показатели развития щенков собак различных пород

\begin{tabular}{|c|c|c|c|c|c|c|c|c|c|}
\hline \multicolumn{2}{|c|}{ Глаза } & \multicolumn{2}{|c|}{ Уши } & \multirow[b]{2}{*}{ Лай } & \multirow[b]{2}{*}{$\begin{array}{c}\text { Хожде- } \\
\text { ние }\end{array}$} & \multirow[b]{2}{*}{$\begin{array}{c}\text { Динамика } \\
\text { массы } \\
\text { тела }\end{array}$} & \multirow[b]{2}{*}{ Зубы } & \multirow[b]{2}{*}{ Порода } & \multirow[b]{2}{*}{ Автор } \\
\hline $\begin{array}{c}\text { Открытие } \\
\text { глазной } \\
\text { щели }\end{array}$ & $\begin{array}{c}\text { Начинают } \\
\text { видеть }\end{array}$ & $\begin{array}{c}\text { Открытие } \\
\text { слухового } \\
\text { прохода }\end{array}$ & \begin{tabular}{|c|}
$\begin{array}{c}\text { Начина- } \\
\text { ют слы- } \\
\text { шать }\end{array}$ \\
\end{tabular} & & & & & & \\
\hline 1 & 2 & 3 & 4 & 5 & 6 & 7 & 8 & 9 & 10 \\
\hline- & $\begin{array}{c}\text { к концу } \\
\text { периода } \\
\text { новорож- } \\
\text { денности }\end{array}$ & - & $\begin{array}{c}\text { к концу } \\
\text { периода } \\
\text { новорож- } \\
\text { денности }\end{array}$ & - & $\begin{array}{c}\text { к концу } \\
\text { периода } \\
\text { новорож- } \\
\text { денности }\end{array}$ & - & - & $\begin{array}{c}\text { служеб- } \\
\text { ные }\end{array}$ & {$[2]$} \\
\hline $\begin{array}{c}\text { через } \\
10 \text { дней }\end{array}$ & - & $\begin{array}{c}\text { через } \\
10 \text { дней }\end{array}$ & - & - & - & - & - & $\begin{array}{c}\text { охотни- } \\
\text { Чьи }\end{array}$ & {$[6]$} \\
\hline $\begin{array}{l}12-14 \\
\text { день }\end{array}$ & - & $\begin{array}{c}12-14 \\
\text { день }\end{array}$ & - & - & - & - & - & $\begin{array}{c}\text { охотни- } \\
\text { чьИ }\end{array}$ & [4] \\
\hline 1 & 2 & 3 & 4 & 5 & 6 & 7 & 8 & 9 & 10 \\
\hline $\begin{array}{l}9-12 \\
\text { день }\end{array}$ & - & 5-8 день & - & - & - & $\begin{array}{c}\text { к } 1 \text { мес } \\
\text { увел. } \\
\text { в 5-6 раз }\end{array}$ & $\begin{array}{c}\text { В конце } \\
\text { 3-4 нед. } \\
\text { появл. } \\
\text { резцы, } \\
\text { а к } 1 \text { мес. } \\
\text { клыки }\end{array}$ & $\begin{array}{c}\text { охотни- } \\
\text { чьи }\end{array}$ & [8] \\
\hline- & 10-12 день & - & $\begin{array}{c}10-12 \\
\text { день }\end{array}$ & - & - & - & $\begin{array}{c}\text { В те-чен. } \\
\text { 3-й нед. } \\
\text { про-реза- } \\
\text { ются } \\
\text { резцы }\end{array}$ & $\begin{array}{c}\text { охотни- } \\
\text { чьи }\end{array}$ & {$[5]$} \\
\hline $\begin{array}{c}\text { через } \\
10 \text { дней }\end{array}$ & - & - & $\begin{array}{r}\text { на 3-й } \\
\text { неделе }\end{array}$ & - & \begin{tabular}{|c|} 
к 3-й \\
нед. \\
начинают \\
неуверен- \\
но ходить
\end{tabular} & - & $\begin{array}{c}\text { пер-вые } \\
\text { зубы по- } \\
\text { являются } \\
\text { через } \\
2-3 \text { нед. }\end{array}$ & $\begin{array}{c}\text { усреднен. } \\
\text { данные } \\
\text { по всем } \\
\text { породам }\end{array}$ & [3] \\
\hline
\end{tabular}




\begin{tabular}{|c|c|c|c|c|c|c|c|c|c|}
\hline \multicolumn{10}{|c|}{ Окончание табл. } \\
\hline 1 & 2 & 3 & 4 & 5 & 6 & 7 & 8 & 9 & 10 \\
\hline $\begin{array}{c}10-13 \\
\text { день }\end{array}$ & - & - & - & - & - & $\begin{array}{c}\text { новор } \\
\sim 300 \text { г } \\
(250-400 \\
\text { г). К } 1 \\
\text { мес. } \\
1700- \\
2100 \text { г. } \\
\end{array}$ & - & $\mid \begin{array}{c}\text { русско- } \\
\text { хотнспа- } \\
\text { ниель }\end{array}$ & {$[1]$} \\
\hline- & $\begin{array}{c}\text { Прозре- } \\
\text { ние на } \\
11-14 \\
\text { день }\end{array}$ & - & $\begin{array}{c}\text { после } 6 \\
\text { суток }\end{array}$ & - & - & - & $\begin{array}{c}\text { первые } \\
\text { зубы начин. } \\
\text { прорез. } \\
\text { после } \\
21 \text { дня }\end{array}$ & спаниели & {$[7]$} \\
\hline- & $\begin{array}{c}12-14 \\
\text { день }\end{array}$ & - & - & - & - & - & - & $\begin{array}{l}\text { англ. } \\
\text { кокер } \\
\text { спан. }\end{array}$ & [9] \\
\hline $\begin{array}{c}\text { через } \\
10-11 \\
\text { суток** }\end{array}$ & - & - & $\begin{array}{l}\text { через } 13- \\
14 \text { суток }\end{array}$ & $\begin{array}{l}\text { через } \\
15-16 \\
\text { суток }\end{array}$ & \begin{tabular}{|c|} 
\\
через \\
$14-15$ \\
суток \\
начинают \\
неуве- \\
ренно хо- \\
дить
\end{tabular} & $\begin{array}{c}\text { новор. } \\
230 \text { г. } \\
\text { К } 1 \text { мес. } \\
1550 \text { г. } \\
\text { (увел. } \\
\text { в 7раз) }\end{array}$ & $\begin{array}{c}\text { через } \\
21-23 \text { сут. } \\
\text { начинают } \\
\text { прорез. } \\
\text { Первые } \\
\text { зубы (рез- } \\
\text { цы). } \\
\text { Через } \\
\text { 30-35 сут. } \\
\text { полностью } \\
\text { вышли } \\
16 \text { зубов } \\
\text { (резцы } \\
\text { и клыки) }\end{array}$ & $\begin{array}{l}\text { англ. } \\
\text { кокер } \\
\text { спан.. }\end{array}$ & $\begin{array}{c}\text { Соб- } \\
\text { ствен- } \\
\text { ные } \\
\text { данные }\end{array}$ \\
\hline
\end{tabular}

* период новорожденности [2]: 1-15 день; ** показатель в сутках = показатель в днях -1 (т.е. через 10 суток $=11$ день).

\section{Заключение}

В результате нашего исследования был получен ряд морфологических и физиологических данных, характеризующих динамику нормального развития щенков английского кокер - спаниеля. Некоторые параметры (в частности, кривая прироста массы тела), повидимому, могут пригодиться заводчикам для выращивания щенков (например, для коррекции кормления). В свою же очередь, сравнительный анализ морфофункциональных показателй развития щенков, проведенный самим заводчиком, поможет будущему владельцу не только «на глаз», но и по объективным критериям выбрать из конкретного помета наиболее здоровую собаку, сроки развития которой совпадают с теоретическими, или даже несколько опережают их.

\section{Список литературы}

1. Айрапетьянц А.Э. Что надо знать владельцу собаки о пустовке,вязке, щенении и выкармливании щенков // Каталог XXIII окружной выставки собак охотничьих и декоративных пород. - Л., 1989. - С. 8-12.

2. Мазовер А.П. Племенное дело в служебном собаководстве. - М.: ДОСААФ, 1960. - С.1-180 .

3. Палмер Дж. Ваша собака: Практическое руководство по выбору и уходу за собакой - М.: Мир, 1988. - С.1 - 168.

4. Платонов А.В. Техника разведения собак // Охотничье собаководство / ред. А.В. Платонов. - М.: Колос, 1966. C.73-79.

5. Пупышев П.Ф. Спортивная охота с собакой. - М.: MO CССР, 1959. - C.1-247.

6. Слимак К., Духай Й. Охотничьи собаки. - М.: Лесная промышленность, 1986. - С.1-336.

7. Спаниель (сборник кинологических материалов).СПб. ВВО ЛенВО, 1998. - С.1-56.

8. Шерешевский Э.И. Разведение охотничьих собак и племенное дело в охотничьем собаководстве. Выбор щенка,содержание,кормление и выращивание охотничьих собак // Пособие по охотничьему собаководству. - М.: Лесная промышленность, 1970. - C.67-106.

9. Herl M. Der Cockerspaniel:Auftzucht, Haltung,Pflege, Ausbildung. Stuttgart: Franckh. 1981. P.1 - 88. 